\title{
STUDY OF DRUG PRESCRIPTION PATTERN OF OBESE AND NON-OBESE PATIENTS WITH TYPE-II DIABETES WITH OR WITHOUT HYPERTENSION
}

\author{
Bajracharya $\mathrm{M}^{1 *}$, Nakarmi $\mathrm{S}^{1}$ \\ ${ }^{1}$ Department of Pharmacy, Manmohan Memorial Institute of Health Sciences, Soalteemode, \\ Kathmandu, Nepal \\ *Corresponding author: \\ Mijala Bajracharya, Lecturer, Department of Pharmacy, Manmohan Memorial Institute of Health \\ Sciences, Soalteemode, Kathmandu, Nepal, Email: bmijala@yahoo.com
}

\section{ABSTRACT}

Background: Obesity is regarded as worldwide health problems which may put a person at a higher risk of serious health conditions leading to morbidity and mortality. Obesity is a risk factor for many diseases of which hypertension and type-2 diabetes mellitus are the most important. Hypertension, diabetes mellitus and obesity together form $24 \%$ of the global risk for mortality. ${ }^{1}$ Cardiovascular diseases related to these life-style disorders has major effect on life expectancy and impaired quality of life. ${ }^{2}$

Objectives: The study was done to evaluate the drug prescribing pattern of type - 2 diabetes and hypertension in both obese and non-obese patients. Along with it, this study also attempt to find the contributing factors associated with it and different types of drugs selected in those conditions respectively.

Method: A descriptive cross-sectional study was conducted in 2074 at Manmohan memorial teaching hospital. A total of 101 out-patient were interviewed, measurements were done to calculate BMI and waist to hip ratio and their prescriptions were reviewed. For Treatment Guideline of HTN, JNC 8[20] was followed and Updated Treatment Guidelines for Type 2 Diabetes by the American Diabetes Association (ADA) [21] was followed in case of diabetes.

Result: Among 101 patients studied, 58 were males and 43 were females. Regarding physical activity, only $26.7 \%$ of total patients were involved in morning walk and $3 \%$ in yoga, remaining $71 \%$ of study patients did not involve in any kind of physical exercise. Regarding food habits, $22.8 \%$ were smokers, $49.5 \%$ were alcoholics and $96 \%$ were non-vegetarians. Waist to hip ratio was also observed higher in both males (35.6\%) and females (39.6\%).Among the101 total participants, the age group of 41-55 years were found to be more obese than other age group (34 in numbers) followed by age group 56-70 which were 16 in numbers. .Male patients were more obese (41) than female patients (31). Highest number(31) of the obese patients were diagnosed with type 2 diabetes mellitus, followed by second highest number (26) of patients diagnosed with hypertension and 15 patients with both the conditions. The commonly prescribed oral 
hypoglycemic drugs were metformin (35.60\%) followed by glimepiride (24.80\%). Among antihypertensive drugs, amlodipine $(22.80 \%)$ was most common in prescriptions followed by losartan (18.80\%) and Telmisartan (17.80\%) .

Conclusion: The results of the present study show that higher number of male patients (41) were obese than female patients (31). . About $30 \%$ of patients were found obese-diabetic, $26 \%$ were obese-hypertensive and $15 \%$ were with both obese diabetic and hypertensive condition. Among oral hypoglycemic drugs, metformin $(35.60 \%)$ was mostly prescribed followed by glimepiride (24.80\%). Among antihypertensives, amlodipine (22.8\%) was mostly prescribed followed by losartan (18.80\%). Atorvastatin (11.9\%) was mostly prescribed oral hypolipidemic agent.

Keywords: Hypertension, Diabetes, BMI, Management 


\section{INTRODUCTION}

Obesity constitute a major health problem worldwide, and since 1980 its prevalence across the globe has doubled. The World Health Organization defines obesity according to body mass index, which is weight in kilograms divided by height in meters squared. Approximately 13 percent of adults around the globe have a BMI of 30 or greater, which categorizes them as obese. Obesity puts a person at a higher risk of serious health conditions, including high blood pressure and cholesterol, type 2 diabetes, heart disease, stroke, gallbladder disease and respiratory problems, as well as some cancers. .Hypertension, diabetes mellitus and obesity together form $24 \%$ of the global risk for mortality. ${ }^{1}$ cardiovascular diseases related to these life-style disorders have major effect on life expectancy and impaired quality of life. ${ }^{2}$

Obesity has become a global epidemic in the past few decades. Among the adult US population, $33.8 \%$ are obese, and another $34.2 \%$ are overweight. ${ }^{3}$.Obesity is a risk factor for many diseases of which hypertension and type diabetes mellitus are the most important. Obese individuals (those with body mass index (BMI) more than $30 \mathrm{~kg} / \mathrm{m} 2$ ) were found to have higher risk for diabetes mellitus and hypertension compared to those with normal body weight. ${ }^{4}$

Overweight individuals also had higher risk for diabetes and hypertension and those with morbid obesity (BMI > $40 \mathrm{~kg} / \mathrm{m} 2$ ) had the highest risk. ${ }^{4}$ As there is a significant linear relationship between body weight and these two diseases, control of excess bodyweight is important for their prevention and treatment. ${ }^{5}$

\section{MATRIALS AND METHODS}

Research Study Type: Descriptive cross-sectional

Research Study Site: Manmohan Memorial Teaching Hospital,Swayambhu-15, Kathmandu, Nepal

Study Population: Patient attending at OPD department of Manmohan memorial teaching hospital (Obese, Diabetic and Hypertensive patients)

Sampling Method: Purposive Sampling

Sample Size: 101 patients

\section{Criteria for sample selection:}

\section{Inclusion criteria:}


1. For Obese Hypertensive and Diabetic patient : Age between 25 and 85 years old, body mass index $>25 \mathrm{~kg} / \mathrm{m} 2$ and waist circumference $>90 \mathrm{~cm}$

2. For Non-Obese Hypertensive and Diabetic patients: Age between 25 and 85 years old

Exclusion criteria: Pregnant or lactating women, Childbirth within 6 months, patients who were under insulin intake treatment, any other conditions deemed unsuitable as evaluated by the physician-in-charge or supervisor.

\section{RESULT AND DISCUSSION}

A total of 101 patients were interviewed. The patients demographic and lifestyle details are listed in table 1 .

Table 1: Demographic and lifestyle details of patients:

\begin{tabular}{|c|c|c|}
\hline Demographic detail & \multicolumn{2}{|c|}{$\%$ in total participants } \\
\hline \multirow[t]{4}{*}{ Age } & $25-40$ & $18.8 \%$ \\
\hline & 41-55 & $45.5 \%$ \\
\hline & $56-70$ & $26.7 \%$ \\
\hline & $71-85$ & $8.9 \%$ \\
\hline \multirow[t]{2}{*}{ Gender } & Male & $57.4 \%$ \\
\hline & Female & $42.6 \%$ \\
\hline \multirow[t]{2}{*}{ Education } & Literate & $48.5 \%$ \\
\hline & Illiterate & $51.5 \%$ \\
\hline \multirow[t]{3}{*}{ Physical Activity } & Morning walk & $26.7 \%$ \\
\hline & Yoga & $3.0 \%$ \\
\hline & None & $71 \%$ \\
\hline \multirow[t]{2}{*}{ Smoking } & Smoker & $22.8 \%$ \\
\hline & Non-smoker & $77.2 \%$ \\
\hline \multirow[t]{2}{*}{ Alcohol consumption } & Alcoholic & $49.5 \%$ \\
\hline & Non-alcoholic & $50.5 \%$ \\
\hline \multirow[t]{2}{*}{ Food habit } & Vegetarian & $4 \%$ \\
\hline & Non-vegetarian & $96 \%$ \\
\hline \multirow[t]{4}{*}{ Waist to hip ratio } & Male $(<0.90)$ & $16.8 \%$ \\
\hline & Male $(>0.90)$ & $35.6 \%$ \\
\hline & Female $(<0.80)$ & $7.9 \%$ \\
\hline & Female $(>0.80)$ & $39.6 \%$ \\
\hline
\end{tabular}


Among 101 patients, 58 (57.4\%) were males and 43 (42.6\%) were females. As per the patients details from interview, it was found that only 29 were involved in physical activity such as Morning walk $(26.7 \%)$ and yoga (3\%) whereas rest $(71 \%)$ patients were involved in none of the physical activities. It was also found that $22.8 \%$ patients were smoker and $49.5 \%$ were alcoholic (table1).It was also found that $96 \%$ of total participants were non-vegetarian, which may be the risk factor causing different obesity related problems.

This shows that age, gender, education, physical activity and food habits have positive association with different disease conditions.

Table 2: Association of Age and BMI

\begin{tabular}{|c|c|c|c|c|c|c|}
\hline \multirow[b]{2}{*}{$\begin{array}{l}\text { Age } \\
\text { (years) }\end{array}$} & \multicolumn{5}{|c|}{ Body Mass Index $\left(\mathrm{Kg} / \mathrm{m}^{2}\right)$} & \multirow[t]{2}{*}{ Total } \\
\hline & $\begin{array}{c}\text { Normal } \\
(\mathbf{1 8 . 5 - 2 2 . 9})\end{array}$ & $\begin{array}{l}\text { Overweight } \\
(23.0-24.9)\end{array}$ & $\begin{array}{c}\text { Obesity I } \\
(25.0-29.9)\end{array}$ & $\begin{array}{c}\text { Obesity II } \\
(30.0-34.9)\end{array}$ & $\begin{array}{l}\text { Obesity III } \\
(>35)\end{array}$ & \\
\hline $25-40$ & 4 & 2 & 10 & 2 & 1 & 19 \\
\hline $41-55$ & 5 & 6 & 26 & 7 & 2 & 46 \\
\hline $56-70$ & 7 & 4 & 9 & 5 & 2 & 27 \\
\hline 71-85 & 2 & 1 & 4 & 2 & $\mathbf{0}$ & 9 \\
\hline
\end{tabular}

Body Mass Index (BMI) was also calculated on the basis of weight and height of the patients. Among the patients, 41-55 years age group of people were obese than other age group (table 2). On the basis of this, higher percentage of male patients were found obese than the female patients (table 3).

Table 3: Association of Gender and BMI

\begin{tabular}{|c|c|c|c|c|c|c|}
\hline \multirow[b]{2}{*}{ Gender } & \multicolumn{5}{|c|}{ Body Mass Index $\left(\mathrm{Kg} / \mathrm{m}^{2}\right)$} & \multirow[t]{2}{*}{ Total } \\
\hline & $\begin{array}{l}\text { Normal } \\
(18.5-22.9)\end{array}$ & $\begin{array}{c}\text { Overweight } \\
(23.0-24.9)\end{array}$ & $\begin{array}{l}\text { Obesity I } \\
(25.0-29.9)\end{array}$ & $\begin{array}{l}\text { Obesity II } \\
(30.0-34.9)\end{array}$ & $\begin{array}{c}\text { Obesity } \\
\text { III } \\
(>35)\end{array}$ & \\
\hline male & 10 & 7 & 28 & 10 & $\mathbf{3}$ & 58 \\
\hline female & 8 & 4 & 23 & 6 & 2 & 43 \\
\hline Total & 18 & 11 & 51 & 16 & 5 & 101 \\
\hline
\end{tabular}

Table 3 reveals the fact that male patients were mainly affected with obese condition in comparison to female patients. 
Table 4: Frequency of DM-2 and HTN in both obese and non-obese patients

\begin{tabular}{|l|r|r|r|r|r|}
\hline & \multicolumn{5}{|c|}{ Body Mass Index (Kg/m²) } \\
\cline { 2 - 7 } Disease Condition & \multicolumn{1}{|c|}{$\begin{array}{c}\text { Normal } \\
(18.5-22.9)\end{array}$} & $\begin{array}{l}\text { Overweight } \\
(23.0-24.9)\end{array}$ & $\begin{array}{c}\text { Obesity I } \\
(25.0-29.9)\end{array}$ & $\begin{array}{l}\text { Obesity II } \\
(30.0-34.9)\end{array}$ & $\begin{array}{l}\text { Obesity } \\
\text { III (>35) }\end{array}$ \\
\hline DM-2 & 5 & 5 & 25 & 5 & 1 \\
\hline HTN & 3 & 5 & 16 & 8 & 2 \\
\hline Both DM-2 and HTN & 10 & 1 & 10 & 3 & 2 \\
\hline Total & 18 & 11 & 51 & 16 & 5 \\
\hline
\end{tabular}

The BMI difference between the Obese and non-obese patients can be clearly seen in the above table 4, which shows that highest number (31) of the obese patients are mainly diagnosed with type-2 Diabetes Mellitus, followed by second highest number (26) of patients diagnosed with Hypertension and 15 patients were found with both the condition.

Table 5: A table showing frequency of different disease conditions.

\begin{tabular}{|c|c|c|c|c|c|c|c|c|c|}
\hline $\begin{array}{l}\text { Disease } \\
\text { Condition }\end{array}$ & 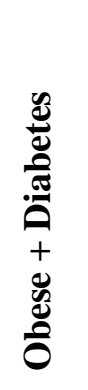 & $\begin{array}{l}Z \\
Z \\
+ \\
\vdots \\
\vdots \\
0 \\
0 \\
0\end{array}$ & 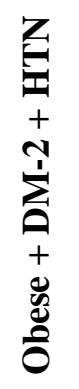 & 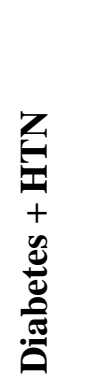 & Z & 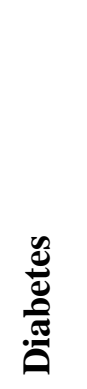 & 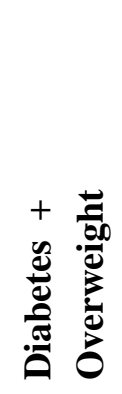 & 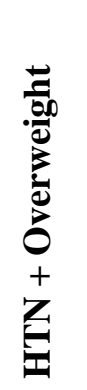 & 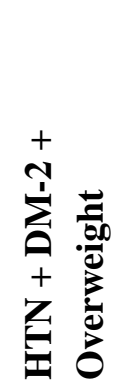 \\
\hline Frequency & 31 & 26 & 15 & 10 & 3 & 5 & 5 & 5 & 1 \\
\hline Total & 101 & 101 & 101 & 101 & 101 & 101 & 101 & 101 & 101 \\
\hline
\end{tabular}

Table 5 reveals the different disease condition among the patients, which is represented in piechart below (Fig 1).

Fig 1: A pie-chart representing different disease conditions in percentage 


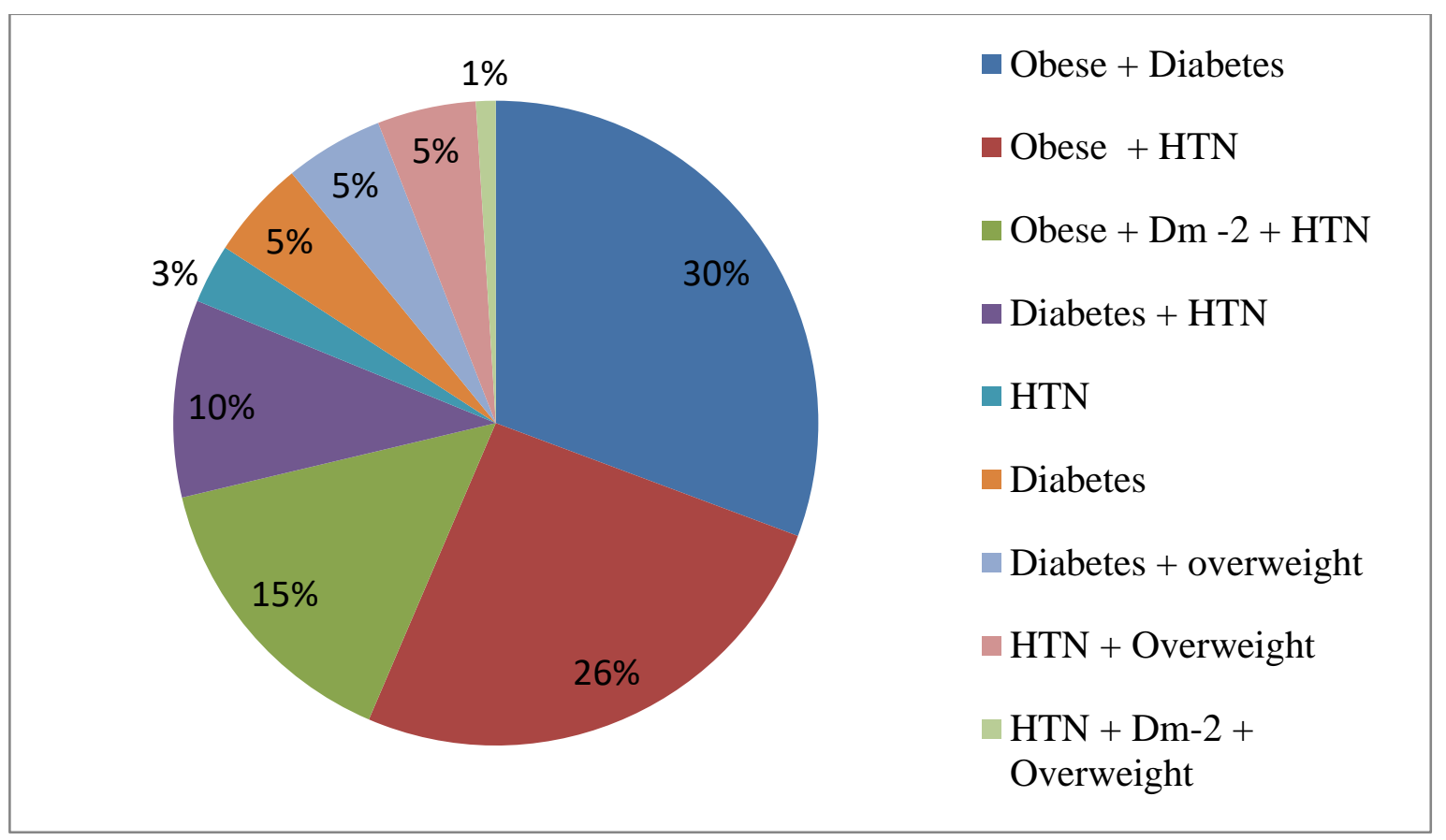

Fig 1 shows that most of the participants i.e. $30 \%$ were suffering from obese-diabetic condition, followed by $26 \%$ participants suffering from obese-hypertensive condition and $15 \%$ participants from both obese diabetic and hypertensive conditions. Only 3\%,5\% and $10 \%$ of participants were non-obese (normal weight) though were hypertensive, diabetic and diabetic-hypertensive respectively. Rest participants were overweight and suffering from diabetes and hypertension or both disease conditions.

Different drugs for the control and treatment of diabetes, hypertension and obese condition were prescribed. Different types of oral hypoglycemic drugs and anti-hypertensive agents prescribed are illustrated in fig 2 and fig3.

Fig 2: Different types of oral hypoglycemic agents prescribed 


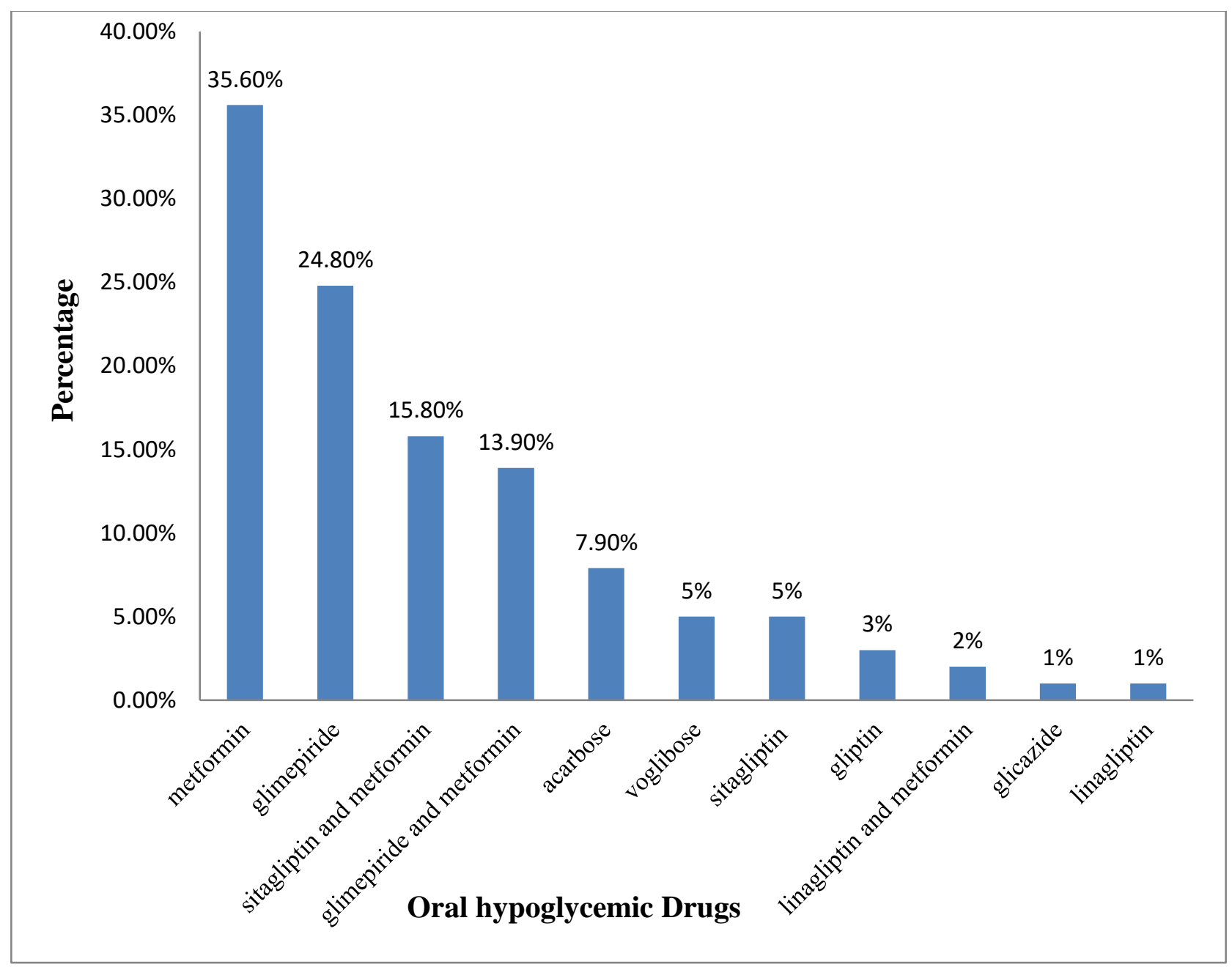

According to fig 2, among all the oral hypoglycemic agents available, metformin (35.60\%) was mostly prescribed, followed by glimepiride (24.80\%), acarbose $(7.9 \%)$, voglibose(5\%),gliptin(3\%), glicazide (1\%) and linagliptine(1\%). Among combination drugs, sitagliptin and metformin $(15.80 \%)$ were prescribed most followed by glimepiride and metformin $(13.90 \%)$ whereas linagliptine and metformin were least prescribed(3\%).

Fig 3 : Different types of Anti-Hypertensive Drugs prescribed 


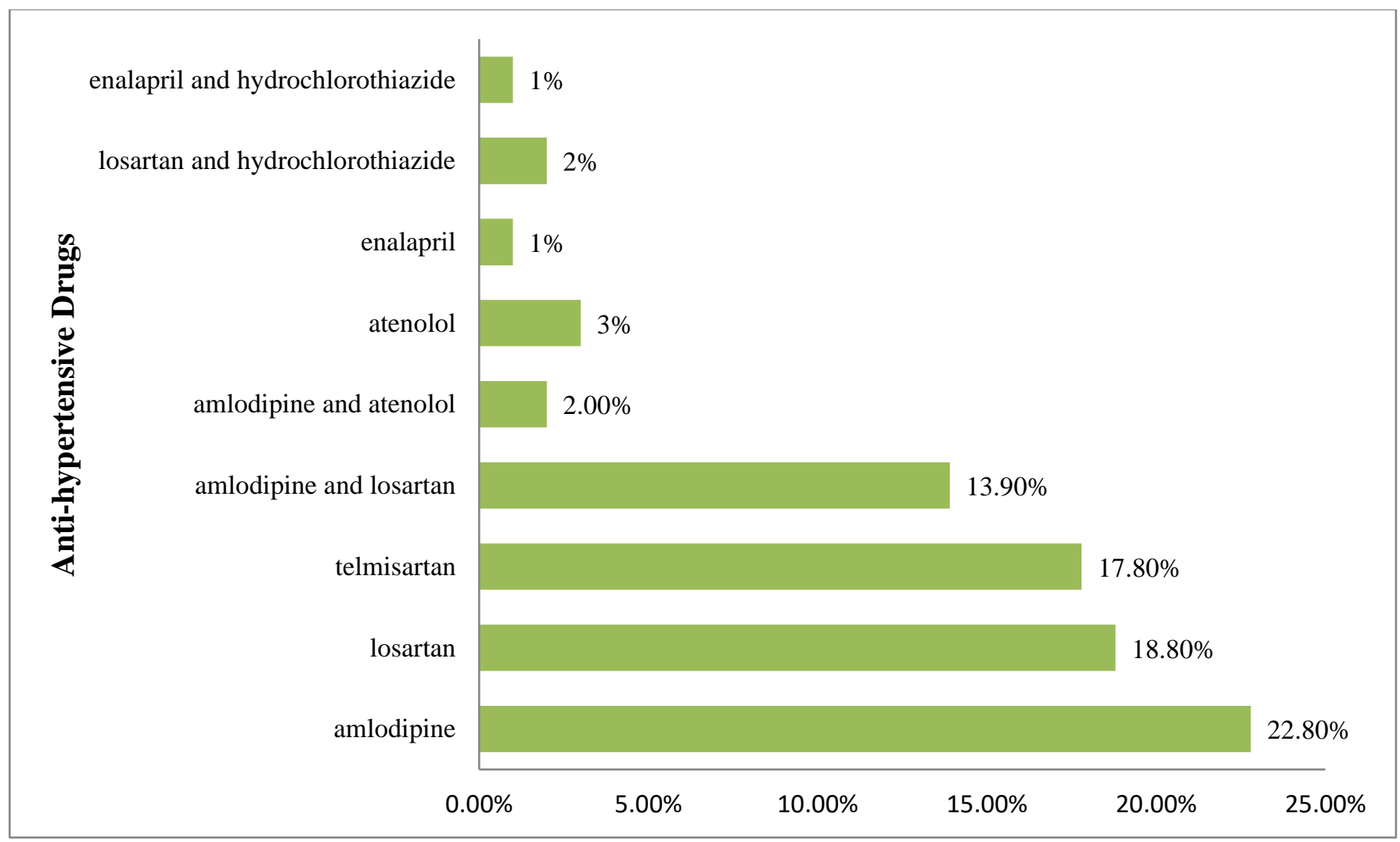

The mostly prescribed single anti- hypertensive agents were amlodipine $(22.80 \%)$ followed by losartan(18.80\%), telmisartan (17.80\%), atenolol (3\%) and enalapril(1\%). Among combined drugs, amlodipine and losartan $(13.90 \%)$ were prescribed most, followed by amlodipine and atenolol (2\%), losartan and hydrochlorothiazide (2\%), enalapril and hydrochlorothiazide (1\%) (fig3). 
Fig 4 : Different types of Oral hypolipidemic agents prescribed in obese condition

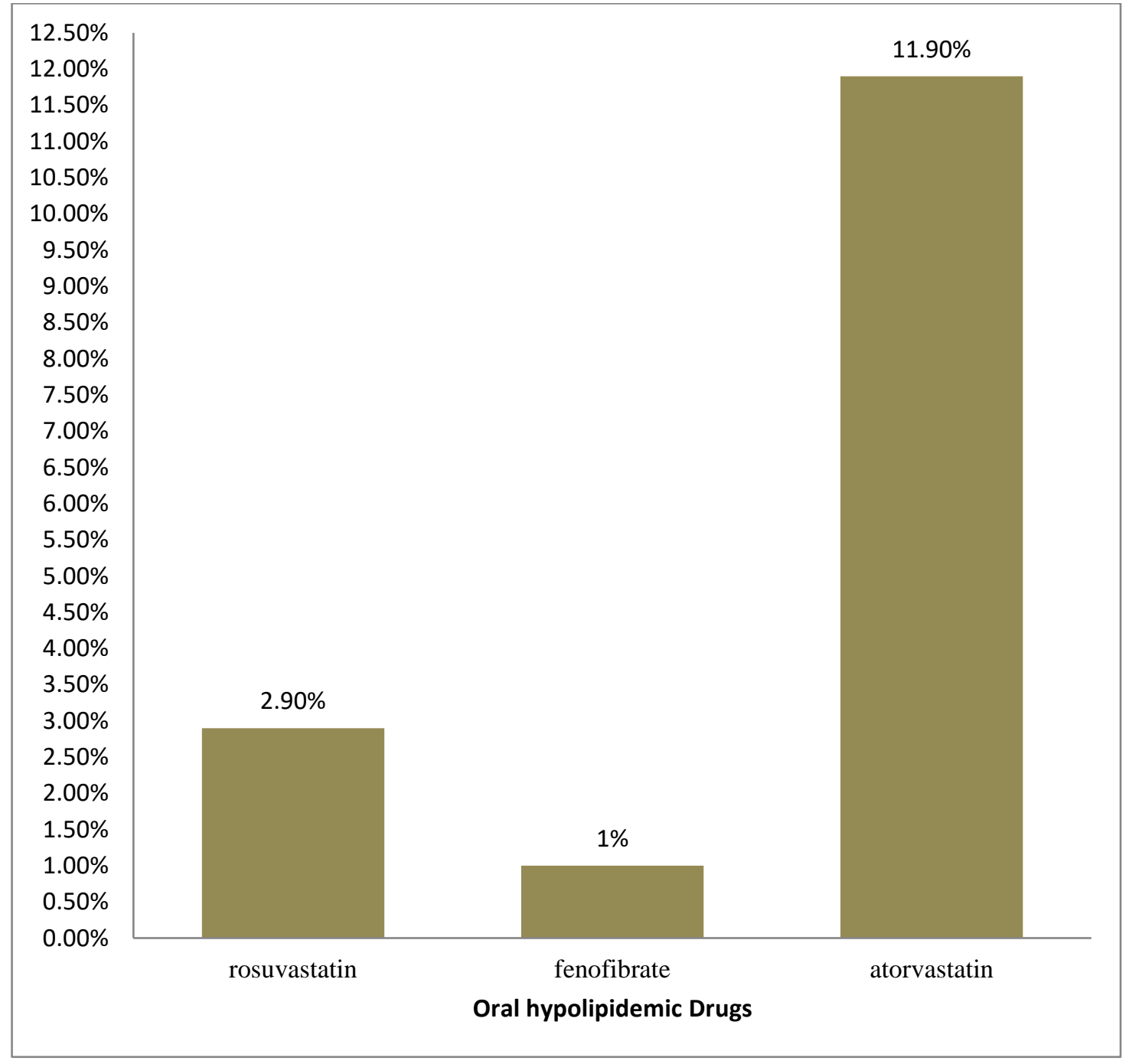

Among oral hypolipidemic agents, atorvastatin (11.9\%) was prescribed most followed by rosuvastatin $(2.90 \%)$ and fenofibrate $(1 \%)$ which is illustrated in fig 4

\section{Table 6: Prescription Indicator}

\begin{tabular}{|l|c|}
\hline Prescription Indicator & Values \\
\hline Average number of drugs per prescription & 2.2 \\
\hline Number of essential drugs per prescription & 0.95 \\
\hline
\end{tabular}


The drugs prescribed to control both hypertension and diabetes were as per the guidelines mentioned earlier. ${ }^{20,21}$

\section{DISCUSSION}

The association between obesity, weight gain with subsequent occurrence of Type II diabetes and high blood pressure has been examined in several prospective studies. ${ }^{6,7,8,9,10,11}$ Increased BMI is now a well-established independent risk factor for the development of Type II diabetes and elevated blood pressure. Body mass index, waist circumference, and hip circumference, all these measures are related to overweight and obesity, were found significantly higher in obese-diabetic and obese-hypertensive subjects than diabetic and hypertensive and non-obese subjects (Table 4, 5 and fig 1). This study showed there is association between age and BMI which can be seen in Table 2.

As per study done by The Nepal Diabetes Association (NDA) ${ }^{12}$, among people aged 20 years and older, $15 \%$ were affected by diabetes while among people aged 40 years and older, this number climbed to $19 \%$.. Study done by Shrestha et $\mathrm{al}^{13}$ in Nepal found that prevalence of hypertension was $22.7 \%$ among urban population aged more than 40 years.

Hypertension is established as one of the most common co morbid conditions in those suffering from diabetes. For instance, study done in Australia showed that around half of diabetic patients had hypertension. ${ }^{14}$ Similar type of studies in China and India also revealed that almost a quarter of hypertensive patients were found to have diabetes. ${ }^{15,16}$ The coexistence of hypertension and diabetes might be because of sharing common risk factors like obesity, smoking, alcohol consumption, unhealthy diets, and lack of physical inactivity.

More recent community based studies in Nepal also showed higher prevalence of hypertension. The study showed there is increment of blood pressure three times higher than previously recorded in suburban Kathmandu. ${ }^{17}$ Another study reported the prevalence of pre-diabetes: diabetes in Nepal to be 19.5:9.5\%. ${ }^{18}$ WHO South East Asia Region Prevalence of diabetes has projected prevalence from 436000 in 2000 to 1328000 in $2030 .^{19}$

\section{CONCLUSION}

The results of the present study show that higher number of male patients (41) were obese than female patients (31). Waist to hip ratio was also higher than prescribed limit in both males $(35.6 \%)$ and females (39.6\%).71\% of total study population were found to be not involved in any kind of physical activity and $96 \%$ were found to be non vegetarian.. About $30 \%$ of patients were found obese-diabetic, $26 \%$ were obese-hypertensive and $15 \%$ were with both obese diabetic and hypertensive condition. Among oral hypoglycemic drugs, metformin (35.60\%) was mostly 


\section{Original Article}

prescribed followed by glimepride (24.80\%). Among antihypertensives, amlodipine (22.8\%) was mostly prescribed followed by losartan (18.80\%). Atorvastatin (11.9\%) was mostly prescribed oral hypolipidemic agent.

\section{REFERENCES}

1. The History of Obesity in the World. Livestrong.com. Leaf Group; 2016 [cited 2017Jun4]. Available from: http://www.livestrong.com/article/380479-the-history-of-obesity-in-theworld

2. World Health Organization, "Global health risks: mortality and burden of disease attributable to selected major risks," December 2010. Available from: http://www.who.int/healthinfo/globalburdendisease/GlobalHealthRisks_report_full.pdfs

3. K. M. Flegal, M. D. Carroll, C. L. Ogden, and L. R. Curtin, "Prevalence and trends in obesity among US adults, 1999-2008," Journal of the American Medical Association, vol. 303,no. 3, pp. 235-241, 2010.

4. A. H. Mokdad, E. S. Ford, B. A. Bowman et al., "Prevalence of obesity, diabetes, and obesityrelated health risk factors, 2001,"Journal of the American Medical Association, vol. 289, no. 1, pp. 76-79, 2003.

5. S. P. Whelton, A. Chin, X. Xin, and J. He, "Effect of aerobic exercise on blood pressure: a meta-analysis of randomized, controlled trials," Annals of Internal Medicine, vol. 136, no. 7, pp. 493-503, 2002.

6. Schmieder, RE, Messerli, FH. Does obesity influence early target organ damage in hypertensive patients? Circulation 1993; 87:1482

7. VasiliosKotsis - Stella Stabouli - Sofia Papakatsika - Zoe Rizos - Gianfranco Parati. Retrieved from: http://www.nature.com/hr/journal/v33/n5/full/hr20109a.html

8. Richard N. Re (2009), Obesity Related Hypertension. Retrieved from: https://www.ncbi.nlm.nih.gov > NCBI > Literature > PubMed Central (PMC)

9. Narkiewicz, Krzysztof. "Obesity and Hypertension-the Issue Is More Complex than We Thought." Nephrology Dialysis Transplantation. Oxford University Press, 25 Nov. 2005. Web. 21 May 2017. <https://academic.oup.com/ndt/article/21/2/264/1850864/Obesity-andhypertension-the-issue-is-more-complex $>$. 
10. Bhupathiraju SN, Hu FB. Epidemiology of obesity and diabetes and their cardiovascular complications. Circ Res. 2016;118:1723-1735 . doi:10.1161/Circresaha.115.306825.

11. Ortega FB, Lavie CJ, Blair SN. Obesity and cardiovascular disease. Circ Res. 2016;118:1752-1770. doi: 10.1161/CIRCRESAHA.115.306883

12. Singh DL, Bhattarai MD. High prevalence of diabetes and impaired fasting glycaemia in urban Nepal. Diabet Med. 2003;20:170-1.

13. Shrestha UK, Singh DL, Bhattarai MD The prevalence of hypertension and diabetes defined by fasting and 2-h plasma glucose criteria in urban Nepal, Diabetic Medicine 2006, vol. 23, no10, pp. 1130-1135 [6 page(s) (article)] (22 ref.)

14. G. E. Caughey, A. I. Vitry, A. L. Gilbert, and E. E. Roughead, "Prevalence of comorbidity of chronic diseases in Australia," BMC Public Health, vol. 8, article 221, 2008.

15. J. Liu, R. Wang, K. Desai, and L. Wu, "Upregulation of aldolaseB and overproduction of methylglyoxal in vascular tissues from rats with metabolic syndrome," Cardiovascular Research, vol. 92, no. 3, pp. 494-503, 2011.

16. K. Venugopal and M. Z. Mohammed, "Prevalence of hypertension in type-2 diabetes mellitus," CHRISMED Journal of Health and Research, vol. 1, no. 4, pp. 223-227, 2014.

17. Vaidya A, Pathak RP, Pandey MR. Prevalence of hypertension in Nepalese community triples in 25 years: a repeat cross-sectional study in rural Kathmandu. Indian Heart J. 2012;64(2):128-31.

18. Ono K, Limbu YR, Rai SK, Kurokawa M, Yanagida J, RaiG, et al. The prevalence of type 2 diabetes mellitus andimpaired fasting glucose in semi-urban population ofNepal. Nepal Med Coll J. 2007;9:154-6. PMID: 18092429.

19. Country and regional data on diabetes. WHO South-East Asia region. Prevalence of diabetes in the WHO South-East Asia Region.

20. James PA, Ortiz E,et.al. Evidence based guidelines for the management of high blood pressure in adults: report from the panel members appointed to the Eight Joint National Committee (JNC 8). JAMA.2014 Feb 5, 311 (5):507-20

21. Standards of Medical Care in Diabetes-2017 Abridged for Primary Care Providers. American Diabetes Association, Clin Diabetes,2016 